\title{
The Effects of Different Concentrations of Retinoic Acid on the Histological Structure of Liver of Adult Albino Female Mice and Their Prenatal Fetuses
}

\author{
Barin Hussien Noori Intissar Numman Waheed* \\ Department of Biology, Faculty of Science, University of Zakho
}

\begin{abstract}
Retinoic acid (RA) an active metabolite of vitamin A, plays essential signaling roles in mammalian embryonic development and adult homeostasis through concentration-dependent activity but in excess, RA is teratogenic. The present study was designed to evaluate the harmful effect of RA on the: liver tissues of the adult pregnant female albino mice and their prenatal fetuses and adult morphological and behavior changes. Forty-five pregnant adult female albino mice were divided into three groups ( $\mathrm{n}=15$ for each group). Group I, the control group orally received $0.1 \mathrm{ml}$ of olive oil. Group II and III received 25 and $50 \mathrm{mg} \mathrm{RA} / \mathrm{kg} \mathrm{B}$.W. respectively. RA was dissolved in $0.1 \mathrm{ml}$ of olive oil and orally given on $7^{\text {th }}, 8^{\text {th }}$, and $9^{\text {th }}$ days of pregnancy. On the $18^{\text {th }}$ day of gestation, these females were sacrificed and the liver from mother and their prenatal were removed, weighed, and prepared for histological study. The RA treated adult group exhibited behavior changes including general fatigue and loss of appetite, in addition to the morphological changes which included weight loss, change in normal red eye color towards black, and redness in the mouth and chin area associated with loss of hair (fur) around this area. These observations were showed to be more severe in the $50 \mathrm{mg}$ RA group. The results showed that treatment with 25 and 50mg RA caused no significant decrease in the adult liver weight, while in their prenatal fetuses 50mg RA caused a higher significant decrease in the liver weight, but $25 \mathrm{mg}$ RA caused no significant effects on this weight. Treated with $50 \mathrm{mg} / \mathrm{kg}$ RA caused a highly significant increase in the number of aborted and dead fetuses as compared with other groups. The results of the histological study showed that treatment with both concentrations of RA caused several degrees of the liver damage with disrupted the normal architecture pattern along with hepatocellular steatosis, hypertrophy, and inflammation. In conclusions, RA caused variable degrees of degeneration and destruction of the liver tissues of adult female (mother) and their prenatal. The most important effects of RA are causing hepatocellular steatosis, hypertrophy, and inflammation, and when RA giving during the critical periods of embryonic development, caused harmful effects on the developing liver, therefore treatment with RA should be avoided at any stage of gestation. Keywords: Liver, retinoic acid, embryonic development, vitamin A, histological study.
\end{abstract}

DOI: $10.7176 / \mathrm{JBAH} / 10-18-04$

Publication date:September $30^{\text {th }} 2020$

\section{Introduction}

Vitamin A and its physiologically active derivative, retinoic acid (RA), participate in many biological conditions, that control normal growth, embryo development, hormonic function, vision, reproduction, the maintenance and modulation of the immune feedbacks, and epithelial tissues and mucosa homeostasis (Cassani et al., 2012; Saeed et al., 2018; Haaker et al., 2020). The human body cannot produce vitamin A in adults nor the embryo (Blomhoff $\&$ Blomhoff, 2006). Therefore, maternal nourishing is the only route of vitamin A intake throughout embryonic development. From the human diet, two pre-cursor forms of vitamin A are obtained, retinol and retinyl ester from meat, and carotenoids ( $\beta$-carotene, $\alpha$-carotene, and $\beta$-cryptoxanthin) from plants. Both are ultimately metabolized into either RA or retinal (retinaldehyde) which is the active metabolite of vitamin A, or they are stored as inactive retinyl esters in the liver or adipose tissue but to a lesser degree (Schreiber et al., 2012).

Retinoic acid is a morphogen derived from retinol (vitamin A). Retinol is metabolized to RA through successive enzymatic reactions catalyzed by distinct sets of dehydrogenases. First, the retinol is oxidized into retinal, which is then oxidized into RA. The RA reacts with the retinoic acid receptor (RAR) and retinoic acid X receptor $(\mathrm{RXR})$. both types encompass three isotypes $(\alpha, \beta$, and $\gamma)$ which affect transcription of several genes during vertebrate development (Linney et al., 2011; Kam et al., 2012).

The normal developing embryo requires retinoids (vitamin $\mathrm{A}$ and its derivatives) in controlled concentrations, any excess or deficiency at the wrong stage and time could potentially have an adverse effect on embryonic development (Sporn \& Roberts, 1991). RA administration can cause a wide range of defects in the central nervous system and neural tube, in addition to defects in the urogenital system, heart, thymus; and limb skeletal, cleft palate, ear, and some other craniofacial defects. This broad range of malformations is observed in the offspring of different species such as humans (Lammer et al., 1985), and rodents (Kessel \& Gruss, 1991).

Retinoid toxicity can be caused by either topical or oral administration. Each one with its own set of adverse effects. Toxicity by oral retinoids can be acute (adults administration of doses as 150-1200 mg over a brief period), chronic (adults administration of doses as $>30 \mathrm{mg}$ over a longer duration of time), and teratogenic (malformation 
of an embryo during pregnancy) (Rutkowski \& Grzegorczyk, 2012). The most typical toxic effect of topical retinoids is skin irritation, accompanied by erythema and peeling. While the most dangerous effect of retinoids is teratogenicity (Hunt, 1996).

Since RA is an important morphogen inducing pattern formation and its excess may disrupt normal development and may lead to serious retardation, and due to the importance of the liver which is considered one of the most essential and hardworking organs that carry out numerous functions in the body such as the breakdown of toxic material from the blood, homeostasis in the body, and metabolism of many substances (McMahon, 2016), the present study was designed to evaluate the harmful effect of two concentrations of RA (25 and $50 \mathrm{mg}$ RA/ $\mathrm{Kg}$. B.W.) on the physical activity and behavior of adult female mice (mother); pregnancy outcome through studying its effects on the life, death, and abortion of prenatal fetuses and histological changes of the liver tissues in adult groups and their prenatal fetuses.

\section{Materials and Methods}

\subsection{Retinoic acid}

Synthetic RA, yellow powder with a molecular weight of $300.44 \mathrm{~g} / \mathrm{mol}$., was used in this study. According to the Naseer \& Tahir, (2012), with some modification, two concentrations of RA were used (25 and $50 \mathrm{mg} / \mathrm{Kg} \mathrm{B}$.W.).

\subsection{Animals and experimental design}

Forty-five pregnant females of strain Balb $\backslash \mathrm{C}$ with average weight $(25-30 \mathrm{gm})$ were obtained from Animal Breeding House $\backslash$ Faculty of Science $\backslash$ Zakho University. These animals were maintained under standard conditions in terms of lighting, temperature, ventilation, and were given feed and water on an ongoing basis (ad libitum).

These pregnant females were divided into three groups $(\mathrm{n}=15$ for each group) and used as follow: Group I: the control group, were received $0.1 \mathrm{ml}$ of olive, group II and III: the experimental group, were received 25 and $50 \mathrm{mg} / \mathrm{kg} \mathrm{B.W}$. /day RA respectively, RA was dissolved in $0.1 \mathrm{ml}$ of olive oil and was given orally on $7^{\text {th }}, 8^{\text {th }}$ and $9^{\text {th }}$ days of pregnancy, while control mice were received olive oil only on comparable days.

\subsection{Dissection and histological preparation}

Before dissection, the morphological changes in the pregnant mice after treated with RA were recorded and photographed. Then on the $18^{\text {th }}$ day of gestation, the females in all groups were dissected and the implantation sites in the uterine horns, the number of intact fetuses, and resorbed embryonic masses were counted. Then the livers of adult female mice and their prenatal were removed; weighted and cut into smaller pieces then fixed in $10 \%$ formalin followed by dehydration, clearing, and embedding in paraffin. Then stained by Harris hematoxylin and eosin (H and $\mathrm{E}$ ) for histological studies and photographing (Bancroft \& Gamble, 2008).

For each group, from fifteen pregnant females, ten adult pregnant females with ten of their prenatal fetuses were dissected and processed for examination in this study with exception of the 50mg RA treated group, because of its effect only one living fetus was obtained from all the 10 mothers.

\subsection{Statistical analysis}

The collected data submitted to Statistical Analysis System (SAS) software (SAS Institute, 2016), in order to analyze the effect of the studied group (factor) using the analysis of variance (ANOVA) one-way method. Results were presented as the mean \pm SE. The differences between the means of groups were analyzed using Duncan's multiple range test. Differences were considered significant when $\mathrm{p}<0.05$ (Duncan, 1955).

\section{Results}

\subsection{Physical activity and behavior}

Observation of adult female mice (mother) of the control groups showed normal growth, activity, and morphological appearance during the experimental period. While in the treated groups, treatment with RA caused adverse effects in the treated animals, these include suppression in their activities and decreased food intake (which resulted into decrease their weight), change in normal red eye color towards black, redness in the mouth and chin area associated with loss of hair (fur) around this area. The severity of these effects was increased by increasing the concentration of RA. Therefore, these effects were more abundant in the group of 50mg RA than a group of 25mg RA (Fig. 1). 

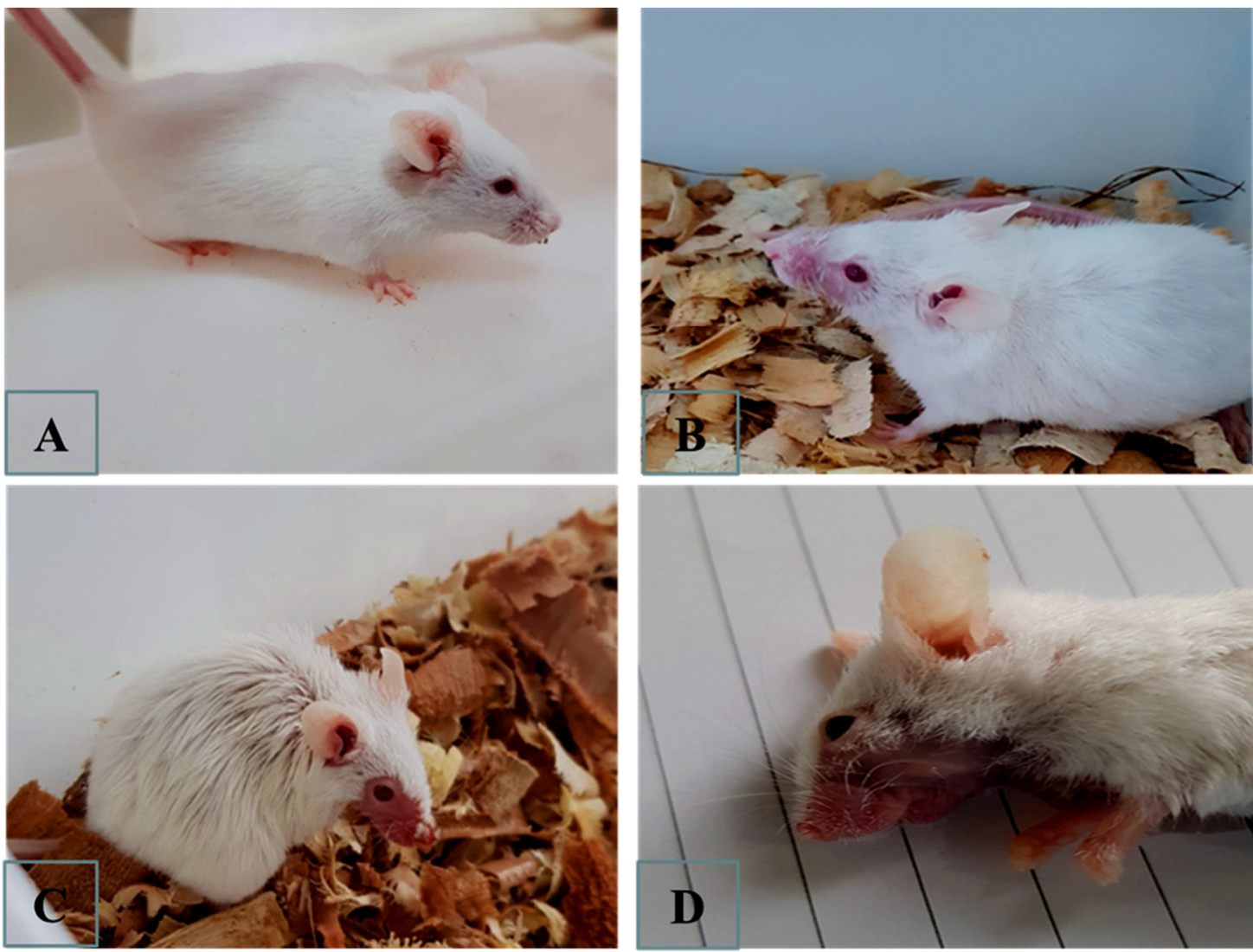

Figure (1): Morphological appearance of the adult female mice during the experimental period. (A) Control group showing the normal morphological appearance of the animal. (B) Shows mild changes in the face of the animal in a group of $25 \mathrm{mg}$ RA. (C and D) treated with $50 \mathrm{mg}$ RA showing the severity changes in the animal of this group including a lot of hair (fur) loss around the face.

\subsection{The effect of retinoic acid on the liver weight of adult female albino mice (mother) and their prenatal fetuses}

No significant effects of 25 and $50 \mathrm{mg}$ RA were observed on the liver weight $(\mathrm{P}>0.05)$ of the adult female mice (mother) as compared to each other or with the control group. While the liver weight in prenatal, the result showed that $50 \mathrm{mg} / \mathrm{kg} \mathrm{RA}$, caused a highly significant decrease $(\mathrm{P}<0.01)$ in their liver weight as compared with the control group. On the other hand, $25 \mathrm{mg} / \mathrm{kg}$ RA had no significant effects $(\mathrm{P}>0.05)$ on their liver weight in comparison with other groups (Table 1).

Table (1): Effect of retinoic acid on the liver weight of adult female albino mice (mother) and their prenatal fetuses (mean \pm S.E).

\begin{tabular}{|c|c|c|}
\hline \multirow{2}{*}{ Groups } & \multicolumn{2}{|c|}{ Liver weight (gm) } \\
\cline { 2 - 3 } & Adult female mice & Prenatal fetuses \\
\hline Control & $1.8807 \pm 0.2706^{\mathrm{a}}$ & $0.0890 \pm 0.0279^{\mathrm{a}}$ \\
\hline $25 \mathrm{mg} \mathrm{RA}$ & $1.8345 \pm 0.2646^{\mathrm{a}}$ & $0.0506 \pm 0.0093^{\mathrm{ab}}$ \\
\hline $50 \mathrm{mg}$ RA & $1.6635 \pm 0.4732^{\mathrm{a}}$ & $0.0409 \pm 0.00^{\mathrm{b}}$ \\
\hline Sig.(p) & NS & $* *$ \\
\hline
\end{tabular}

Similar letters within each column refer to the non-significant $(\mathrm{P}>0.05)$, while different letters in the same column refer to significant differences $(\mathrm{P}<0.05)$. NS $=$ non-significant; $* * \mathrm{P}<0.01=$ highly significant.

\subsection{The effects of retinoic acid on the pregnancy outcome}

As shown in Table (2), there were no significant differences $(\mathrm{P}>0.05)$ in the total number of pregnancy outcomes among all groups. But as the results of the RA treatment, the concentration of $50 \mathrm{mg} / \mathrm{kg}$ RA caused the death of these fetuses and resulted in a highly significant increase $(\mathrm{P}<0.01)$ in the number of aborted fetuses if compared with other groups. This table also showed that treatment with $25 \mathrm{mg}$ RA caused a highly significant increase in the number of aborted fetuses compared with the control group. 
Table (2): The effects of retinoic acid on the pregnancy outcome (mean \pm S.E).

\begin{tabular}{|c|c|c|}
\hline Adult groups & Pregnancy outcome & Abortion number \\
\hline Control & $5.20000 \pm 1.9322^{\mathrm{a}}$ & $0 \pm 0.00^{\mathrm{c}}$ \\
\hline 25mg RA & $5.3000 \pm 1.7029^{\mathrm{a}}$ & $4.3000 \pm 2.7101^{\mathrm{b}}$ \\
\hline 50mg RA & $6.8000 \pm 1.9889^{\mathrm{a}}$ & $6.7000 \pm 1.9465^{\mathrm{a}}$ \\
\hline Sig.(p) & NS & $* *$ \\
\hline
\end{tabular}

Similar letters within each column refer to the non-significant $(\mathrm{P}>0.05)$, while different letters in the same column refer to significant differences $(\mathrm{P}<0.05)$. NS= non-significant; $* * \mathrm{P}<0.01=$ highly significant.

\subsection{Histological study of the RA effects on the liver tissues of adult female mice (mother)}

Microscopic examination of the liver sections of the adult group showed normal histological architecture of the liver with no pathological appearance (Fig. 2 A, B, and C).
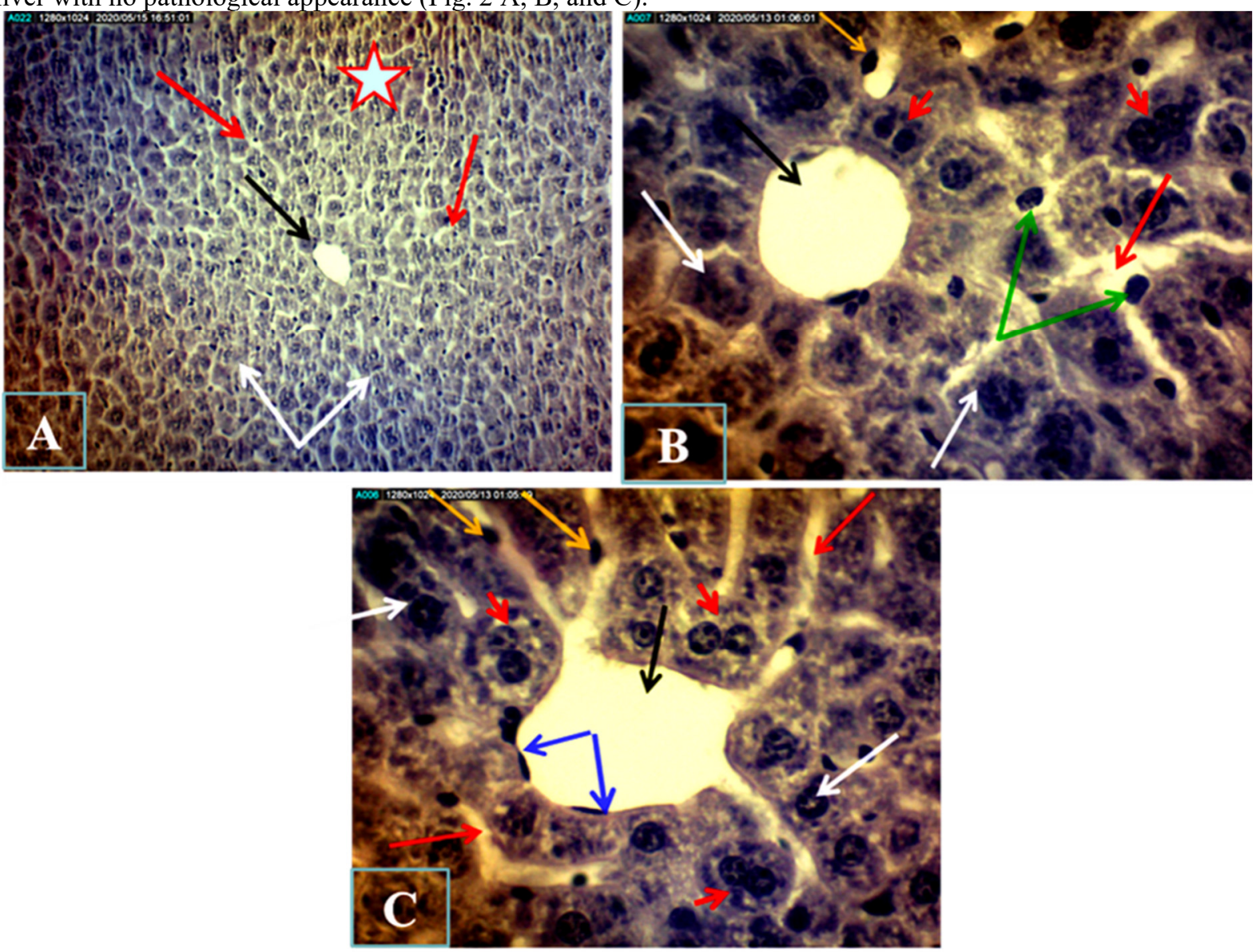

Figure (2): (A, B and C) Transverse sections through the liver of adult female albino mice (mother) (control group) showing normal appearance of the liver structure; Liver parenchyma (red star), central vein (black arrows) with flat endothelial lining (blue arrows), polygonal hepatocytes radiating from the central vein with rounded vesicular nuclei (white arrows), Binucleated cells (small head red arrows), Kupffer cells (green arrows), narrow radiating blood sinusoids in between liver cords (long red arrows) and their lining endothelial cells (yellow arrows) (H\&E, A: $100 \mathrm{X}, \mathrm{B}$ and $\mathrm{C} 400 \mathrm{X}$ ).

The result of the present study showed that treated with $25 \mathrm{mg}$ RA caused several damages to the adult liver tissue; these damages are presented in figures $(3,4$, and 5$)$. The most effective of this concentration was causing hepatic steatosis (fatty liver diseases) (Fig. 4A, B, and D and 5A). This fatty degeneration included the formation of macrovesicular steatosis which appeared with large lipid droplets and this droplet displacing the nucleus of the hepatocyte to the periphery of the cell in addition to the presence of microvesicular steatosis appeared with small lipid droplets are present in hepatocytes (Fig. 4D). Ballooning hepatocytes (hypertrophy and vacuolated cytoplasm) and macrovesicular steatosis with large lipid droplets are present in hepatocyte also were detected (Fig. 5D).

Despite these changes, it has been observed the presence of healthy binucleated hepatocytes (which looked in large numbers in the liver tissue) (Fig. 3D, 4C and 5A), normal hepatocytes (Fig. 3C) and (4B and D), megakaryocyte cells (Fig. 3B and C), and hematopoietic cells (Fig. 4C). These findings indicate the ability of 
liver regeneration and its hematopoietic function.
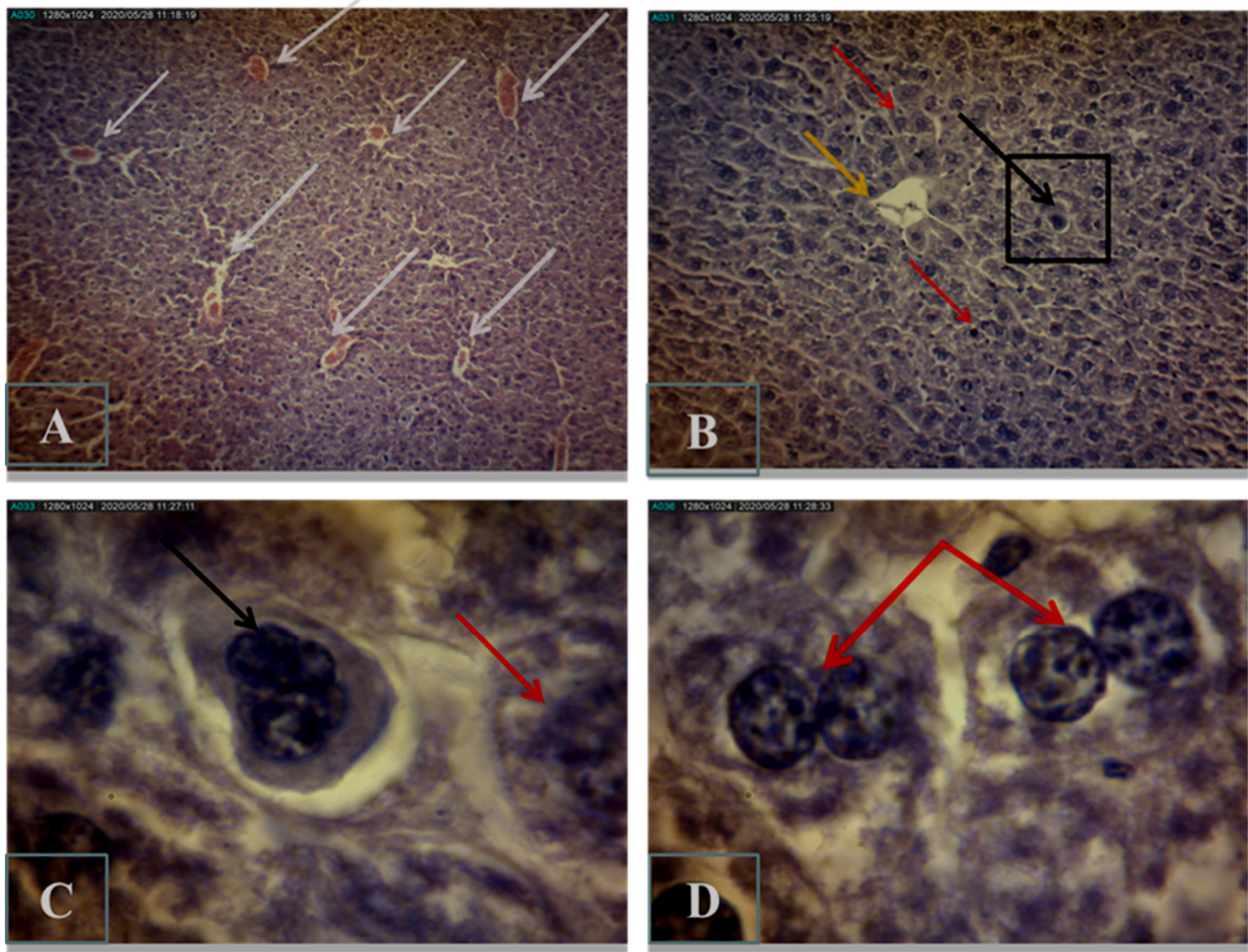

Figure (3): Transverse sections through the liver of adult female albino mice (mother) treated with $25 \mathrm{mg}$ RA showing: (A) Branching and congestion of central veins (white arrows). (B) Sheets of Hepatocytes branching from the central vein (yellow arrow), dead some of the hepatocytes (red arrows), notice the presence of megakaryocyte (Black arrow). (C) Higher magnification of the megakaryocyte in (B); red arrow indicates the normal hepatocyte. (D) Two binucleated hepatocytes are seen (red arrows). (H\&E, A 40x, B 100x, C and D 1000X). 

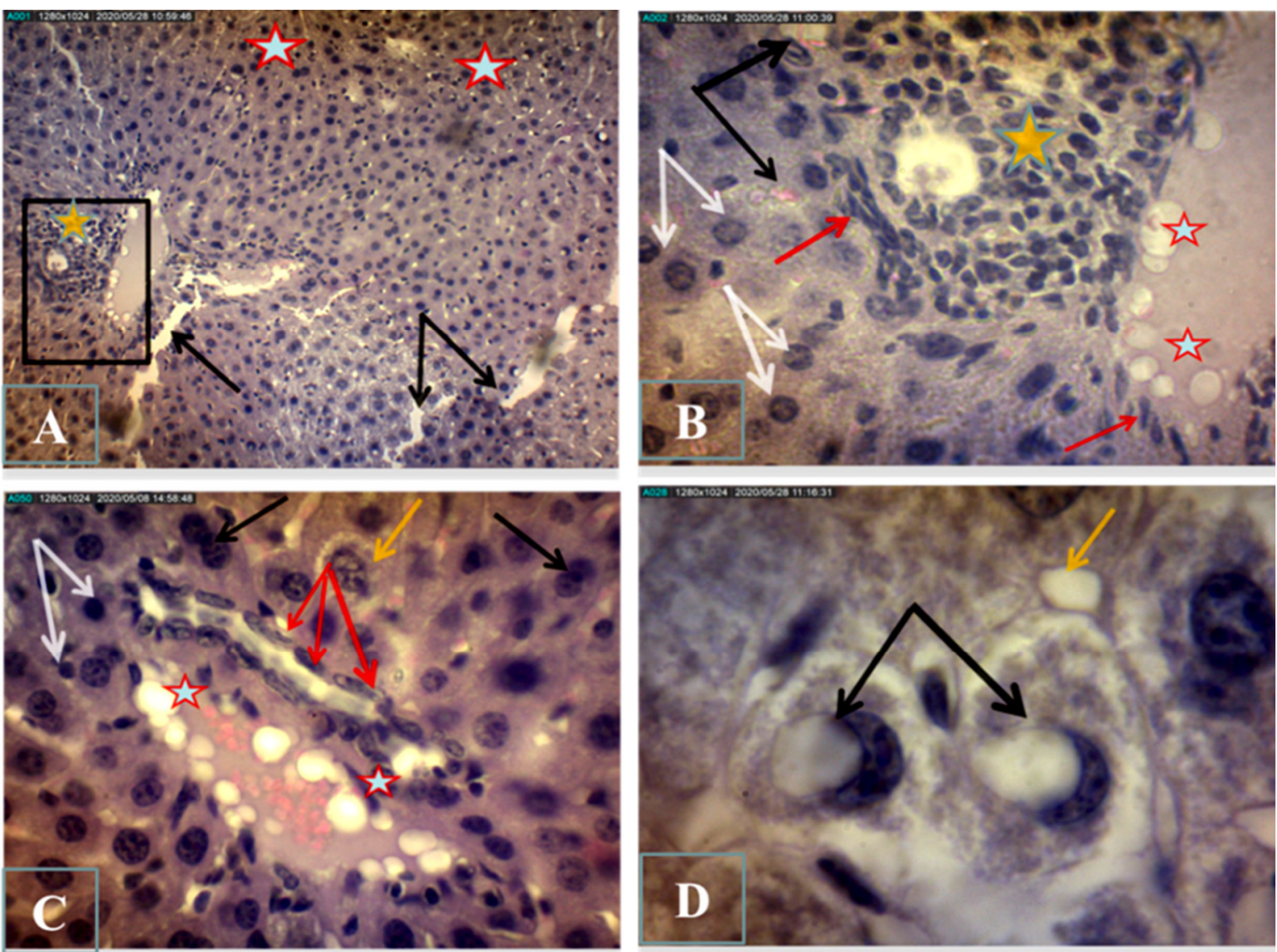

Figure (4): Transverse sections through the liver of adult female albino mice (mother) treated with $25 \mathrm{mg}$ RA showing: (A) foamy degeneration changes in the liver parenchyma and cells (red stars) which is known as hepatic steatosis (fatty liver disease), dilation in the lumen of sinusoids (black arrows), inflammatory cells infiltration (yellow star). (B) Higher magnification of part of (A) this figure indicates the presence of lipid droplet (red stars), aggregation of inflammatory cells (yellow star) associated with the presence of fibroblast cells (red arrows); RBC (black arrows) and normal hepatocytes (white arrows). (C) Presence of binucleated hepatocytes (black arrows), RBC (red stars), dead some of the hepatocytes (white arrows), fibroblast cells (red arrows), and hematopoietic cell (yellow arrows). (D) Two macrovesicular steatoses (Black arrows), and yellow arrow indicate microvesicular steatosis (H\&E, A 100x, B and C 400x and D 1000x). 

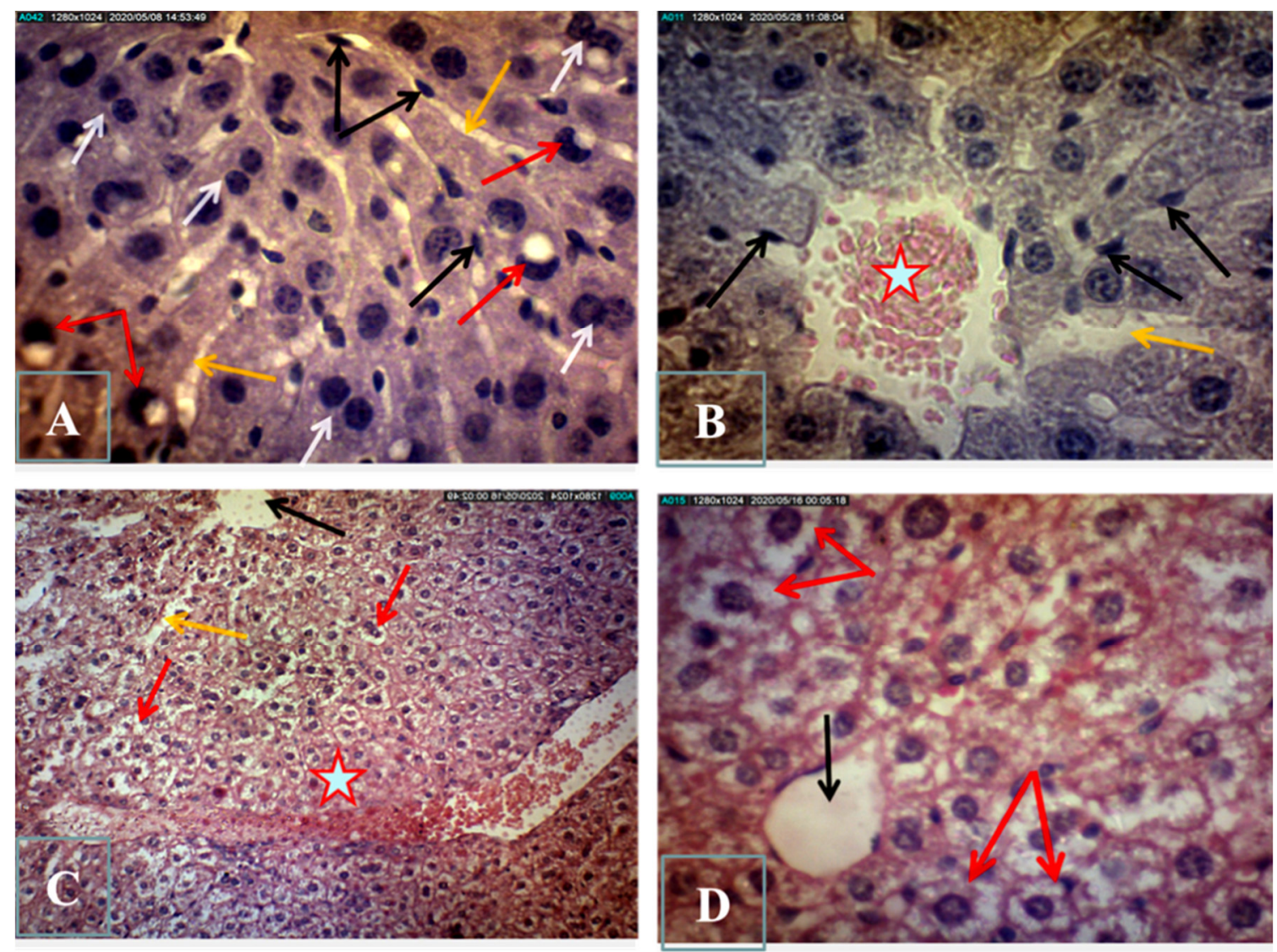

Figure (5): Transverse sections through the liver of adult female albino mice (mother) treated with $25 \mathrm{mg}$ RA showing: (A) foamy degeneration changes in the liver cells (red stars), binucleated hepatocytes (white arrows), sinusoids (yellow arrows) and their lining endothelial cells (black arrows). (B) Congested central vein (red star), slightly dilated sinusoid (yellow arrow) with endothelial lining (black arrows). (C and D) In general, these figures showed the disruption of normal architecture pattern of liver parenchyma, in $(\mathrm{C})$ notice the elongation and dilation of blood vessel associated with severe hemorrhage (red star), dilation of the sinusoid (yellow arrow), central vein (black arrow), ballooning hepatocytes (red arrows). (D) Higher magnification of ballooning hepatocytes (hypertrophy and vacuolated cytoplasm) (red arrows), Macrovesicular steatosis- large lipid droplets are present in hepatocyte (black arrow). (H\&E, A, B and D 400x, C 100x).

Treatment with 50mg RA caused severe degeneration in the adult liver tissues; this degeneration was illustrated in figures $(6,7$, and 8$)$.

As in the group of $25 \mathrm{mg}$, the liver sections of this group showed the presence of some of the normal hepatocytes and binucleated cells but, in less number, if compared with the group of $25 \mathrm{mg}$ RA (Fig. 6D), (7A and D) and (8B and C). 

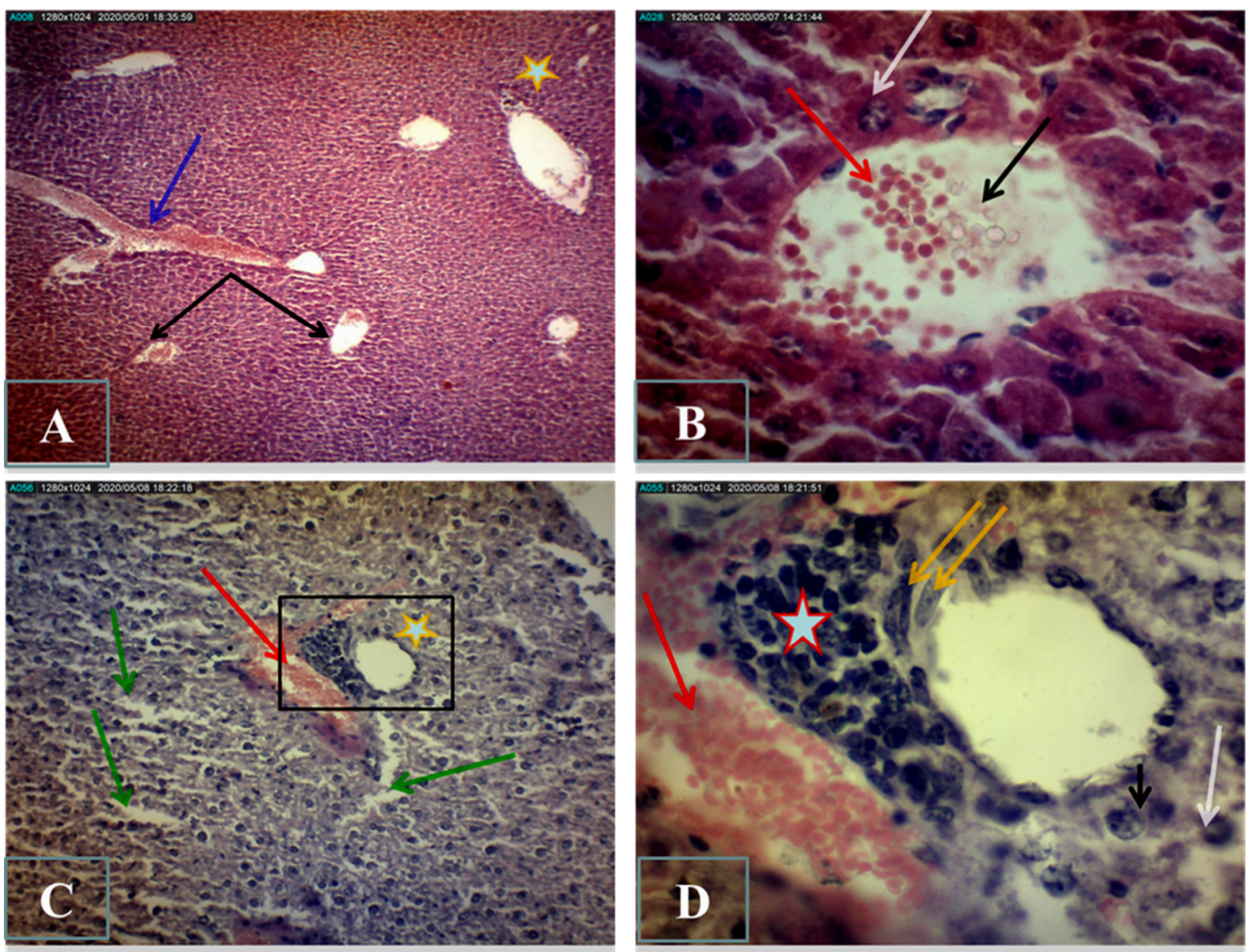

Figure (6): Transverse sections through the liver of adult female albino mice (mother) treated with 50mg RA group showing several degrees of liver damages: (A) Dilation and congestion of the blood vessels (blue arrow) and central vein (black arrow) and inflamed portal area (blue star). (B) High power of congested central vein containing RBCs (red arrow) and lipid droplets (black arrow), white arrow indicates the hepatocyte. (C) Dilation of the sinusoid (green arrows), Vasodilation and RBCs infiltration surrounding the portal area (red arrow), inflamed portal area (yellow star); (D) Higher magnification of the portal are on (C) indicate Leukocytes infiltration (red star) and RBCs accumulation (red arrow), Fibroblast cells (yellow arrows); White arrow indicates the hepatocyte and small black arrow the Binucleated hepatocyte cell. (H\&E, A 40x, C 100x, C and D 400x). 

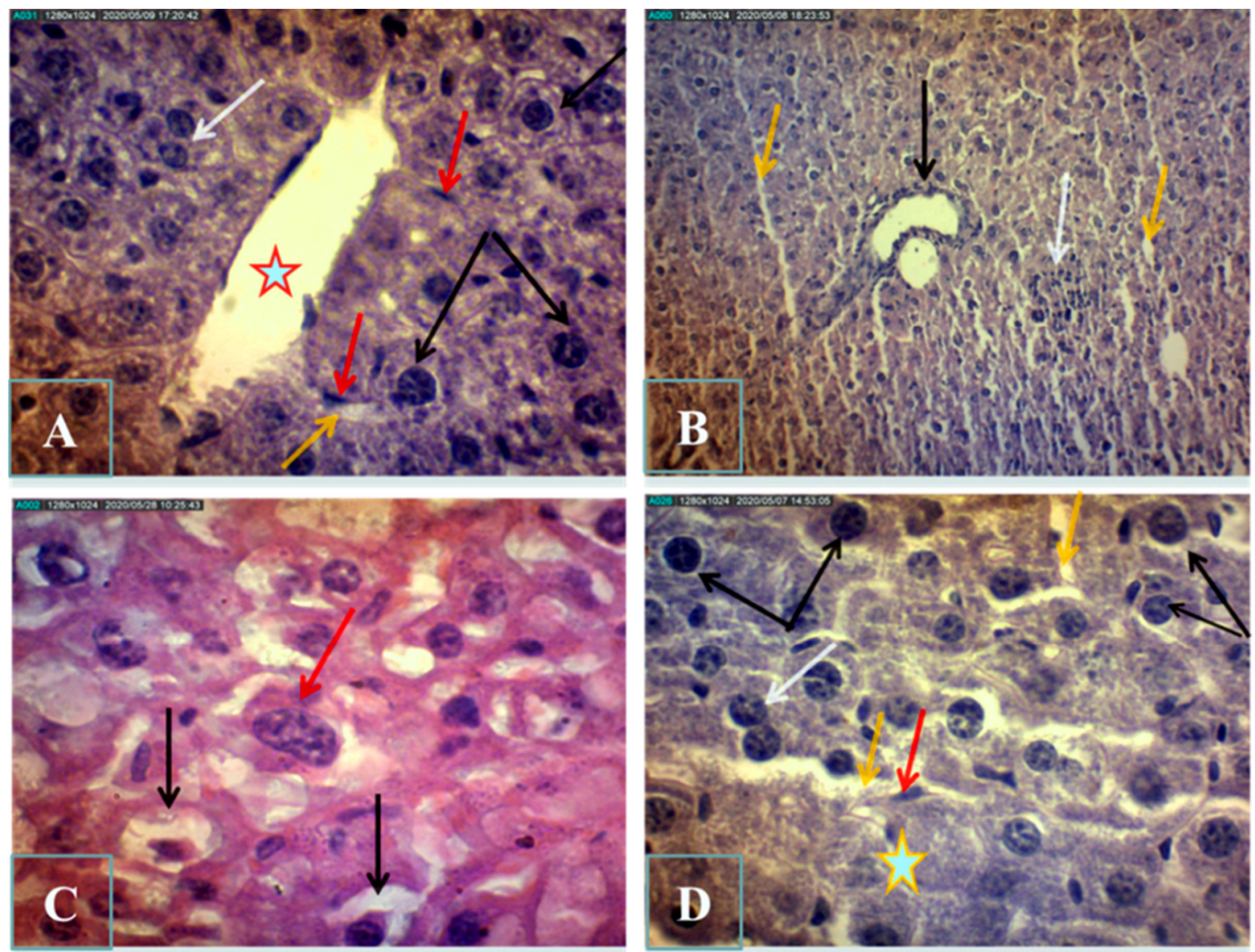

Figure (7): Transverse sections through the liver of adult female albino mice (mother) treated with 50mg RA group showing: (A) Elongation and dilation of central vein (red star), binucleated hepatocytes (white arrow), sinusoid (yellow arrow) with endothelial cell lining (red arrows) and vesicular hepatocytes (black arrow). (B) Black arrow indicates the portal area with mononuclear infiltrate, area of necrotic foci is also present (white arrow), slightly dilation and elongation of sinusoids (yellow arrows). (C) Dysplastic cell (red arrow), hypertrophy and vacuolated cytoplasm of hepatocytes (black arrows) (D) Binucleated cells (white arrow), normally looked hepatocytes (black arrow), Sinusoid (yellow arrow) with endothelial cell lining (red arrows), and damaged of liver parenchyma (yellow star). (H\&E, A, C and D 400x, B 100x). 

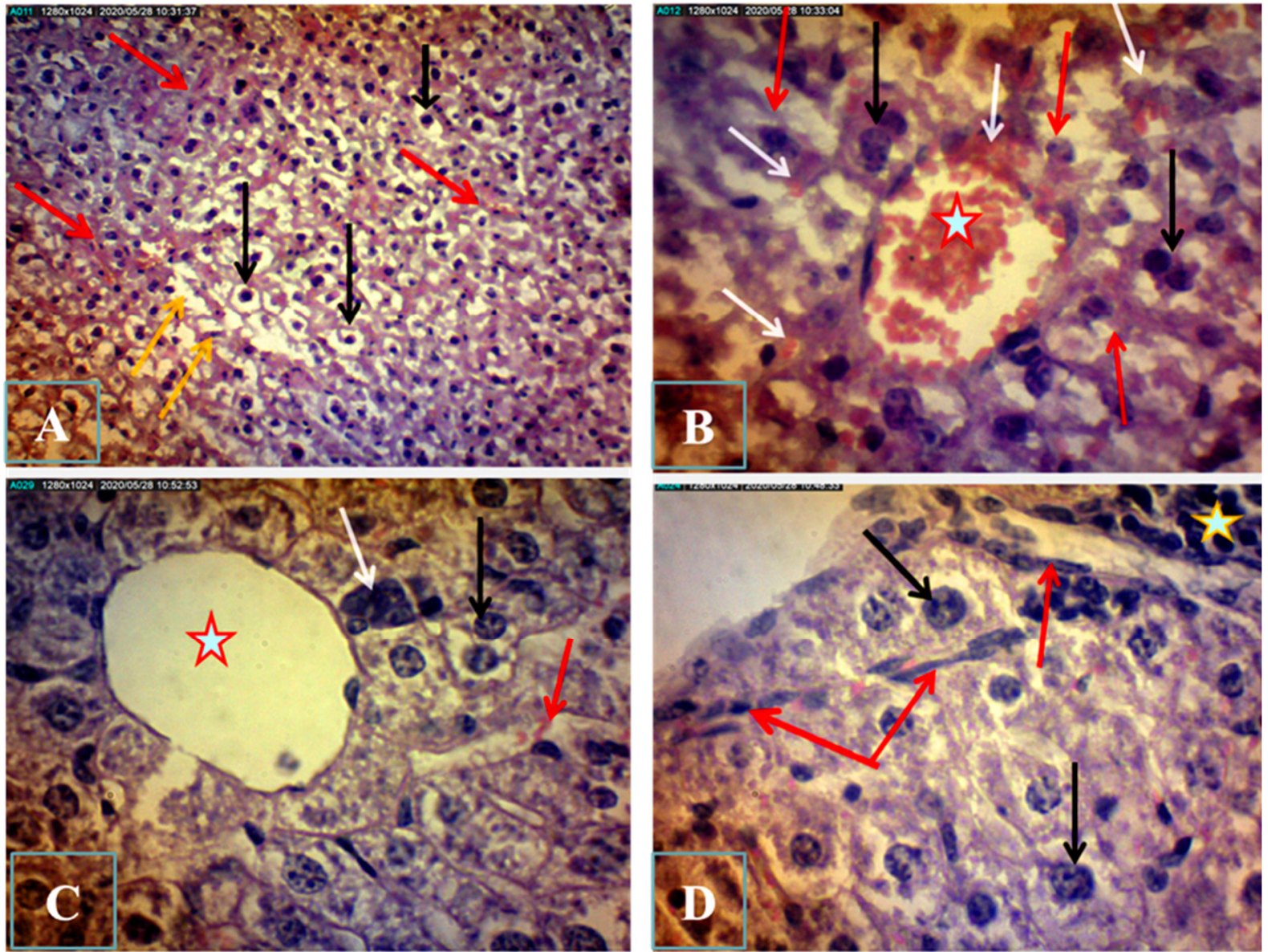

Figure (8): Transverse sections through the liver of adult female albino mice (mother) treated with 50mg RA group showing disruption of normal architecture pattern of classical lobules: (A) hypertrophy of hepatocytes associated with vacuolated cytoplasm (black arrows), vacuolar degeneration of hepatocytes (yellow arrows) and necrotic area (red arrows). (B) Congested central vein with destroyed margin (red star) surrounding by degenerative hepatocytes, which resulted in the RBCs diffusing between surrounding tissues (white arrows), binucleated cells (black arrows), and dead hepatocytes (red arrows). (C) Increase the size of central vein (red star), dilation and congested sinusoid (red arrows), binucleated cell (black arrow), multinucleated cell (white arrow). (D) This figure indicates the inflamed area of liver parenchyma, notice the presence of fibroblast cells (red arrows), and inflammatory cells (yellow star), some of the hepatocytes appeared slightly increased in their sizes (black arrows). (H\&E, A 100x, B, $\mathrm{C}$, and D 400x).

\subsection{Histological studies of the effect of RA on the liver of prenatal fetuses}

In the control group, the liver sections of the prenatal showed normal appearance as indicated in figures $(9 \mathrm{~A}, \mathrm{~B}$, C, D, E, and F). These figures showed that the liver in this stage of development consists of hepatocytes, blood sinusoids, central and portal veins. As demonstrated in (Fig. 9C and E), the hepatocytes gain increased contact with each other to form hepatic cords. Figure (9A) showed these hepatocytes are normal, large in size, and flat in shape. Generally, in mammals, it is well known that the liver is the main site of hematopoiesis during prenatal development, therefore the figures of the control group showed many hematopoietic cells found scattered individually and in foci among liver parenchyma.

Histological evaluation of the prenatal liver after exposing their mothers to $25 \mathrm{mg}$ RA revealed that this concentration caused adverse effects on the liver tissue; these effects are presented in figures (10 and 11). This concentration also caused fatty degeneration in the liver tissue (Fig. 11C and D); these figures showed the formation of foamy hepatocytes in which the cell's nuclei were located within the center of the cells without the displacement that commonly occurs.

Normal and healthy mononucleated and binucleated hepatocytes and lymphocytes also were detected in these sections (Fig. 10D).

More histological alterations were detected in the liver of the prenatal of 50mg RA. All the prenatal of this group were aborted except one of them. The liver sections of this animal revealed the degeneration of the liver tissue (Fig. 12 A, B, C, and D). From the liver results of adult (mother) and their prenatal, it appears that treatment 
with RA (both concentrations) caused hepatocellular steatosis, hypertrophy, and inflammation.
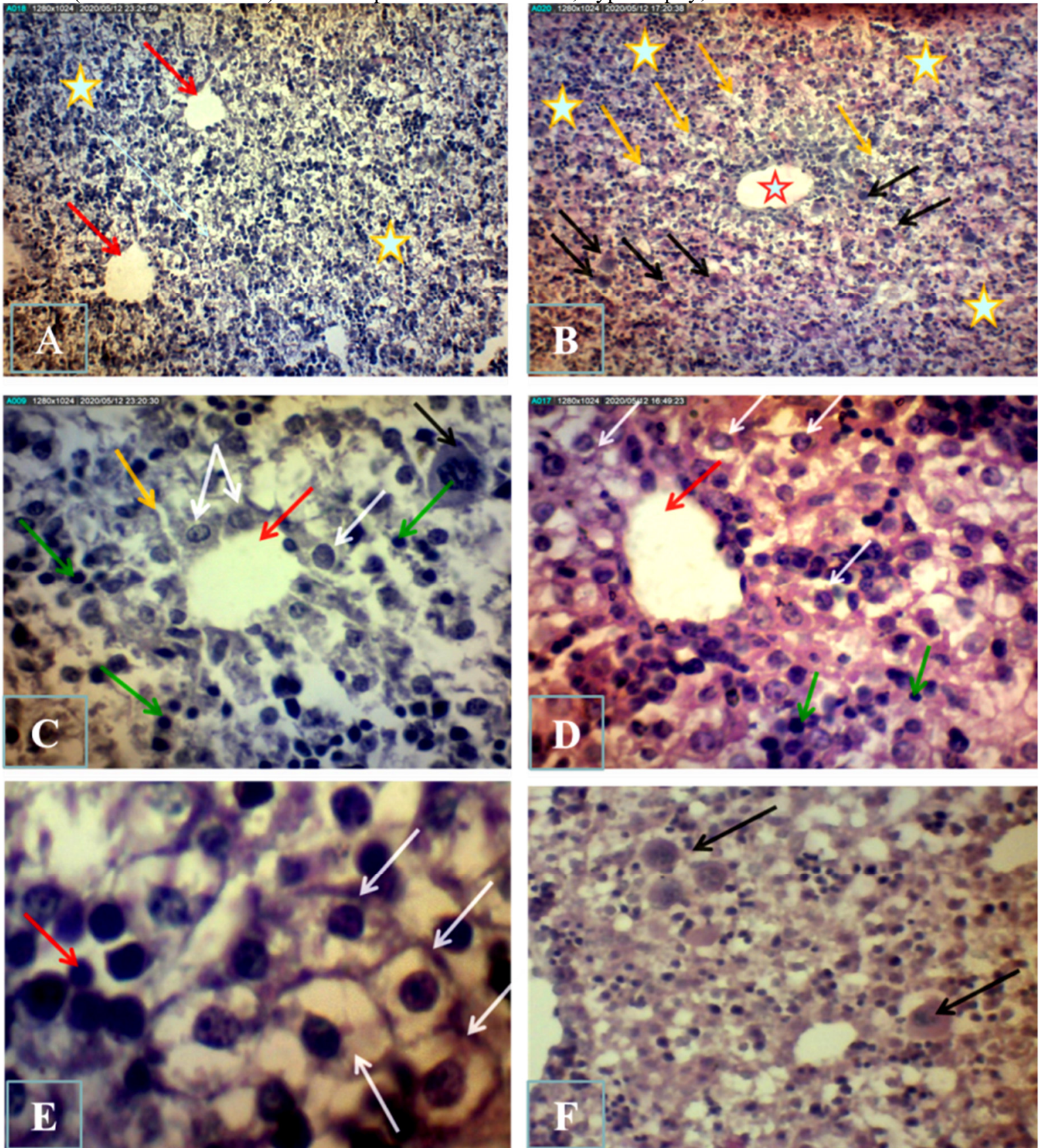

Figure (9): (A, B, C, D E, and F) Transverse sections through the liver of prenatal albino mice (control group) showing the normal histological architecture of the liver tissues including central vein (red arrows), portal vein (red star) notice dense infiltration of hematopoietic cells mostly lymphocytes around the portal vein, blood sinusoid (yellow arrows), hematopoietic cells (black arrows), Lymphocytes (green arrows), hepatocytes (white arrows), and yellow stars indicates to the mononuclear cell infiltration in the liver parenchymatous tissue. (E) Higher magnification of the normal hepatocytes (white arrows) and Lymphocytes (red arrows). (F) Showing hematopoietic cells (black arrows). (H\&E, A and B. 100x, C, D and, F 400x, E 1000x,). 

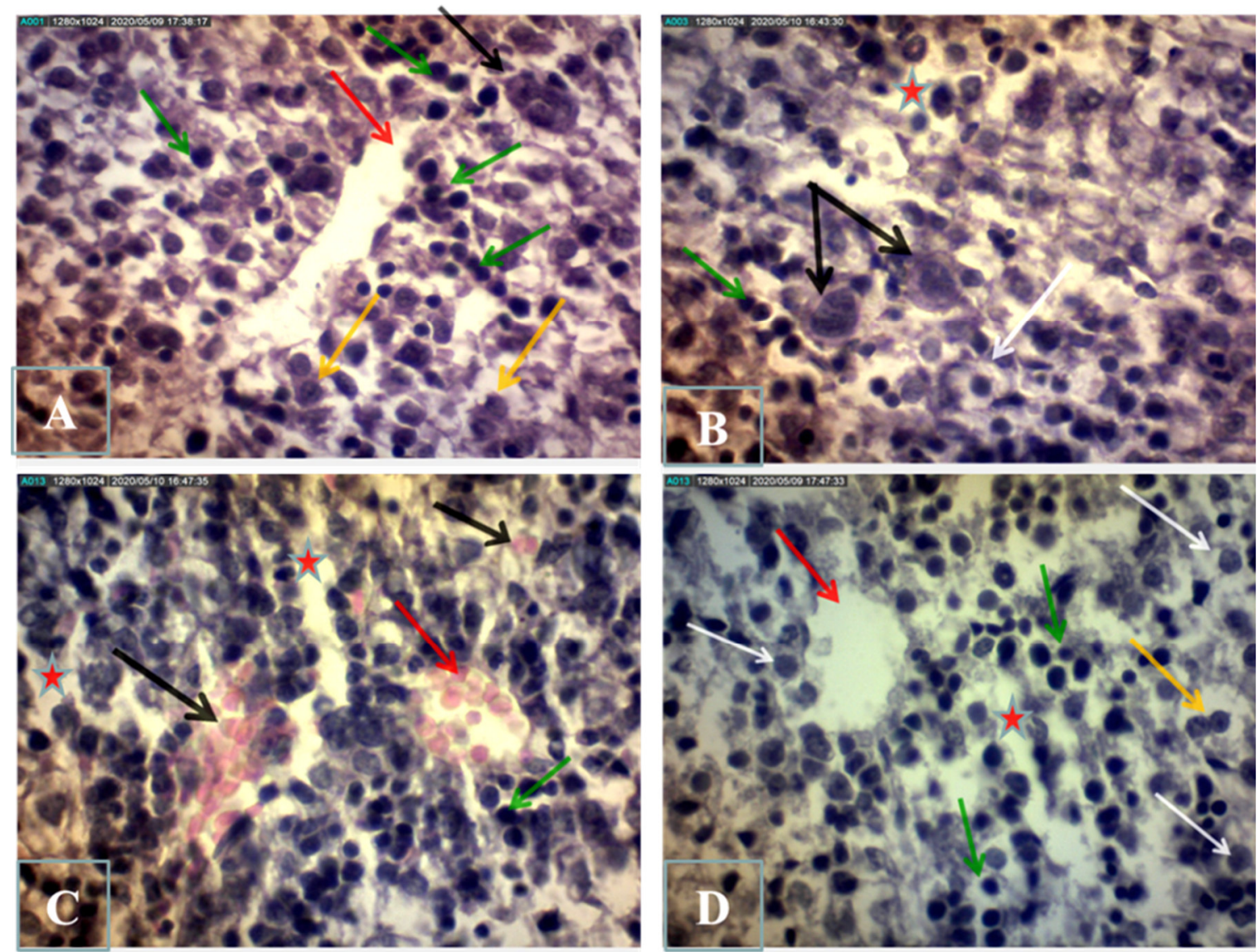

Figure (10): Transverse sections through the liver of prenatal albino mice treated with $25 \mathrm{mg}$ RA group showing some adverse effects of this concentration on the liver tissues in addition to the presence of some normal structures: (A) Increase the size and length of the central vein (red arrow), binucleated cells (yellow arrows), Lymphocytes (green arrows), and megakaryocyte with multilobed nuclei are seen in A and B (black arrows). (B) Hepatocyte (white arrow) note the area around the nuclei suggesting fatty degeneration in the liver, lymphocytes (green arrow), and sinusoid (red star). (C) This figure demonstrates the presence of RBCs in the central vein (red arrow) and among liver parenchyma (black arrow), sinusoid (red stars), lymphocytes (green arrow). (D) This figure indicates the presence of the normal mononucleated (white arrows) and binucleated hepatocytes (yellow arrow), lymphocytes (green arrows), and central vein (red arrow). (H\&E, A, B, C, and D 400x). 

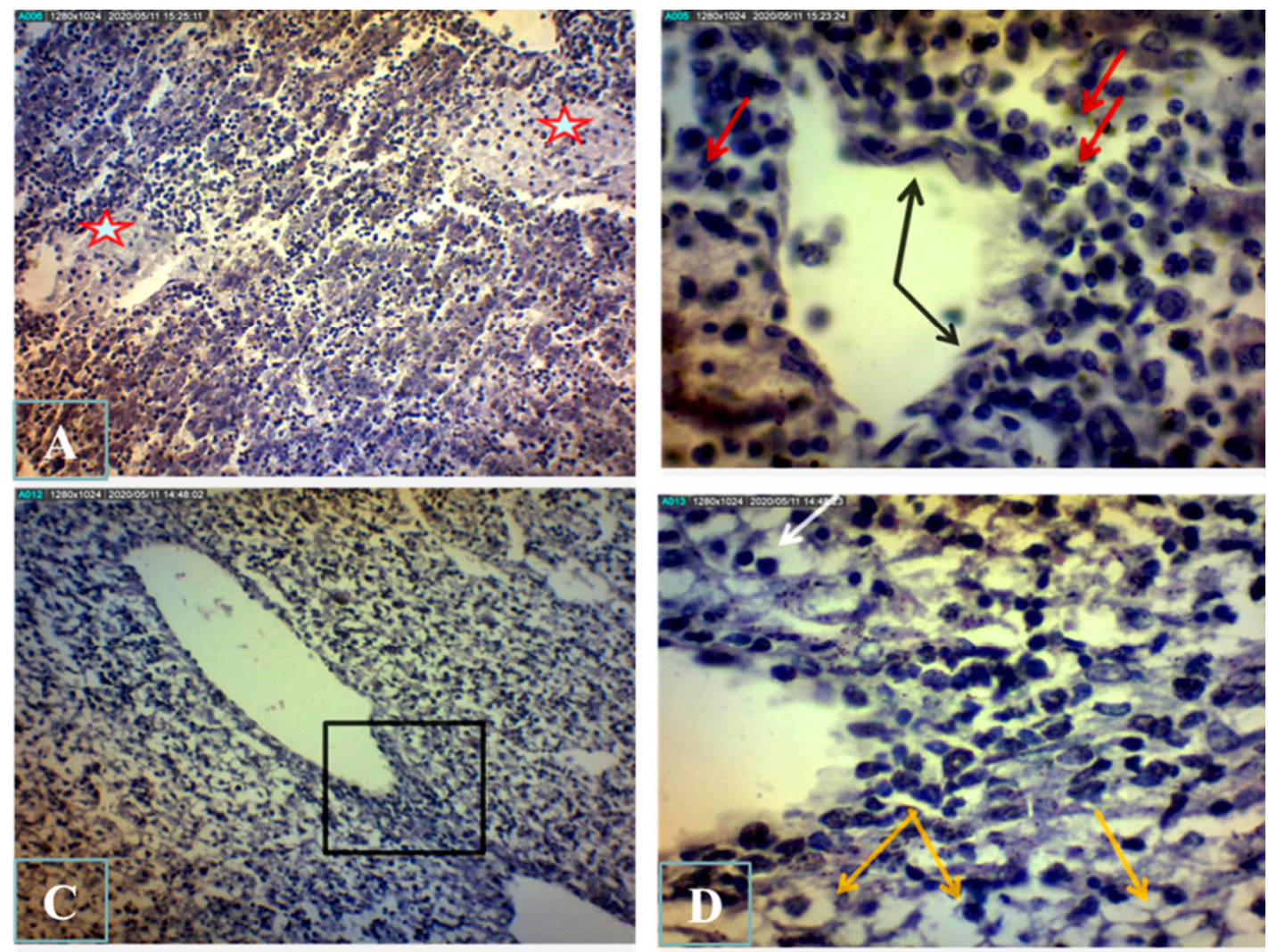

Figure (11): A, B, C and D, transverse sections through the liver of prenatal albino mice treated with $25 \mathrm{mg}$ RA group showing mononuclear cell infiltration in the liver parenchymatous tissue: (A) Infiltration of fibrinous materials (red star) among liver parenchyma (B) fibroblast cells (black arrows) notice the presence of apoptotic bodies (red arrows). (C) This figure indicates fatty degeneration in the liver, also this figure showed dilation and elongation of the blood vessel. (D) Higher magnification of part of figure C) showed the presence of dead binucleated cell (white arrow), and foamy hepatocytes (yellow arrows) in which the cells nuclei are located within the center of the cell without the displacement that commonly occurs. (H\&E, A and C 100x, B and D 400x). 

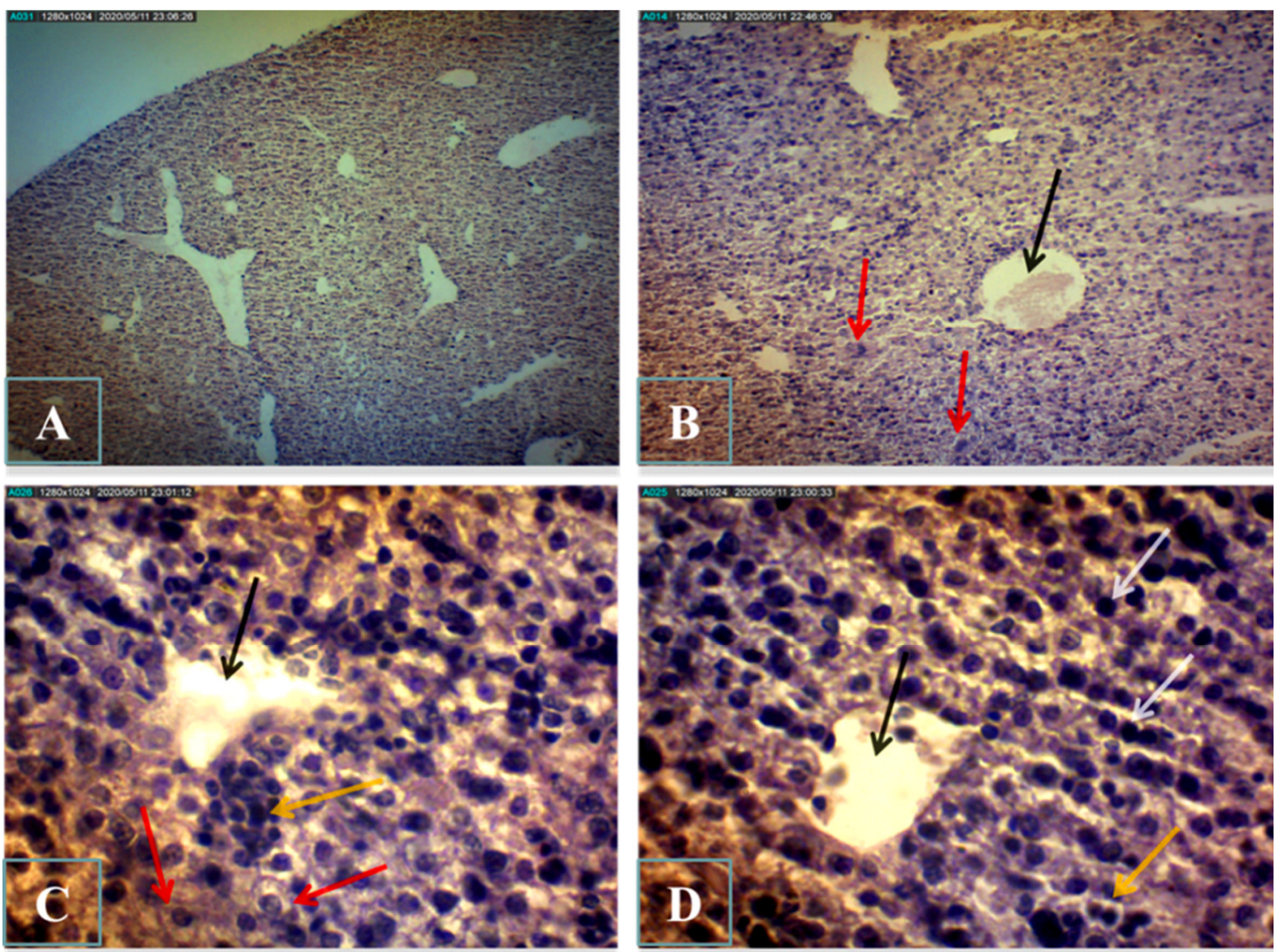

Figure (12): A, B, C and D, transverse sections through the liver of prenatal albino mice treated with 50 mg RA group showing: (A) Degeneration of the liver tissue and vasodilation and congestion of blood vessels. (B) Dense infiltration of hematopoietic cells around the central vein (black arrow) and in the parenchymatous tissue, megakaryocyte cells (red arrows) also seen. (C) Foci of mononuclear cell (yellow arrow) which also infiltrated in the parenchymatous tissue, deforming central vein (black arrow) and red arrows indicate the hepatocyte. (D) Deforming central vein (black arrow), dead binucleated cell (yellow arrow), and white arrows the lymphocyte cells. (H\&E, A 40x, B 100x, C and D 400x).

\section{Discussion}

In the present study RA was given orally on $7^{\text {th }}, 8^{\text {th }}$, and $9^{\text {th }}$ days of gestation, these days as indicated by Rugh, (1968) and Stromland et al., (1991) are considered to be a critical time for organogenesis in mice, since liver diverticulum is reported to be formed by $9^{\text {th }}$ days, and proliferates cells rapidly beginning of $91 / 2$ days gestation shortly thereafter epithelial cords appear in the liver primordial (Rugh, 1968).

Many authors such as Okano et al., (2012), Kelly \& Drysdale, (2015), Canete et al., (2017), khaksaryMahabady et al., (2018), Zasada \& Budziz, (2019) and Roberts, (2020) reported the important role of RA during embryogenesis and for tissue homeostasis in both embryo and adult. In the embryo, RA homeostasis in a regionspecific manner is in many ways the reason determining proliferation and differentiation of the developing cells. For this reason, in the developing embryo, the concentration of RA must be cautiously controlled in both time and space. In general, RA overdosing is well known as a teratogen and results in particular patterns of abnormalities implicating many individual organ systems eventually causing birth defects (Ross, 2002; Piersma et al., 2017; Noori \& Waheed, 2020 (unpublished data)). Therefore, in the present study when the pregnant female was treated with RA during gestation periods mentioned above, this treatment caused damage to the liver tissue in both mother and prenatal fetuses. This result is in agreement with the results of Morriss-Kay and his colleague (1991), they showed that mouse administered $12 \mathrm{mg} / \mathrm{kg}$ RA dose on day 7 or 8 of gestation caused overall developmental retardation.

The result of the present study showed the exposure of adult female mice to the RA (25 and $50 \mathrm{mg}$ ) caused suppression in their activities and decreases of food intake, these observations are in agreement with the result of Aguwa et al., (2016), Their results revealed that when the rats were exposed to an overdose (400 and $500 \mathrm{mg} / \mathrm{kg}$ ) of vitamin A for 14 days resulted in general body fatigue, decreased food and water uptake and the rats become smaller, shrunk, weak, and waif. The loss of appetite is a symptom seen in many case reports of hypervitaminosis A and during the administration of medication analogs to vitamin A metabolites $(\mathrm{NIH}, 2017$; Vallerand et al., 
2018; Babatola et al., 2019). Another effect of RA was the loss of hair (fur) around the mouth, this finding is in agreement with Okano et al., (2012), this report demonstrated that hair loss is associated with excess administration of RA. The dark eye was also noticed during the morphological examination of treated adult mice, all-trans-retinoic acid (atRA) a metabolite of RA has been detected in the retina. In the outer connective tissue shell of the eye, the sclera it is speculated that atRA controls the expression of numerous genes that influence changes in scleral extracellular matrix readjusting ocular size and refraction (Summers, 2019). Adverse effects on the visual system have been documented with confidence from the medication containing RA (Suuberg, 2019).

Results of the present study also showed that treatment with RA leads to the death and abortion of the prenatal fetuses, this was well documented in the group of 50mg RA which caused a higher significant increase in the number of aborted adults and death of fetuses compared with the other groups. Furthermore, the entire live adult (mother) in this group had dead fetuses except one of them was found alive, this finding is in agreement with Ross, (2002), their result indicated that RA is being toxic and leading to the spontaneous abortion. Result of Mao et al., (2000) are found in agreement with the result of the recent study, their results indicated that retinol dosage of 20 or $40 \mathrm{mg} / \mathrm{kg}$ did not increase embryo lethality or alter litter size, while the dosage of $60 \mathrm{mg} / \mathrm{kg}$ of retinol increased in embryo lethality, and dosage of $80 \mathrm{mg} / \mathrm{kg}$ caused high embryo lethality (92.5\%). In 2016, Aguwa et al. also reported treatment with an overdose of vitamin A (400 and $500 \mathrm{mg} / \mathrm{kg}$ ) caused spontaneous abortion and death of the fetuses.

4.1 Histological studies of the RA effects on the liver of adult female mice (mother) and their prenatal fetuses The liver is the largest gland in the body and it is composed principally of epithelial cells (hepatocytes), which are bathed in blood-derived from the hepatic portal veins and hepatic arteries. Therefore, there is a continual chemical exchange between the blood and the cells (Moore \& Dalley, 2018). The liver is the main site of detoxification and is principally the major site of intense metabolism by being very critical in the breakdown and removal of toxic or potentially toxic material through the blood. Therefore, the liver has a tendency to various disorders as a result of its exposure to various toxins in extrinsic and intrinsic forms (Guyton \& Hall, 2006).

Result of the present study has shown that both concentrations of RA caused a non-significant decrease in the weight of the liver of the adult female mice if compared with the weight of the control, while in their prenatal fetuses, group of $50 \mathrm{mg}$ RA showed a higher significant decrease in the liver weight compared with the other groups. This result is in agreement with Barandeh et al., (2019), who demonstrated that RA applies toxic effects on the development of the embryonic organ in a dose and time-dependent manner. But the present result was disagreement with Mahassni \& Al-Shaikh, (2014) they showed no connection between oral intake of vitamin A and liver weight in rats.

Treatment with RA caused several histological alterations in the liver tissues of RA treated female mice and their prenatal fetuses so its caused vasodilation, elongation, and congestion of the blood vessels, sinusoids, and central veins, associated with severe hemorrhage and inflammatory cells infiltration in the liver parenchyma. These results are in agreement with other studies such as Mehrotra \& Shah, (2004), their results showed that intraperitoneally administration to low dose of vitamin A $\left(7.5 \mathrm{mg} / \mathrm{kg} \mathrm{B}\right.$.W.) once as a single dose in day $11^{\text {th }}$ of gestation caused elongation and disruption of the central vein, and this resulted in severe hemorrhage. Yousef \& Azizzadeh, (2010) also showed that RA caused disruptive effects on the vascular systems, such as an increase in the diameter of the sinusoids in embryonic liver tissue. In 2019, Barandeh et al. showed that when pregnant female mice were treated in day $10^{\text {th }}$ of gestation with $60 \mathrm{mg} / \mathrm{kg}$ all-trans RA via diet caused cavity formation in the liver tissue, increase in sinusoids diameter, and disruption of epithelial cells arrangement.

Another effect of RA which recorded in the present study was the degeneration of hepatocytes, damaged and severs inflammation among the portal area and liver parenchyma, in addition to the formation of necrotic foci, multinucleated cells, and apoptotic bodies. These findings are in agreement with Tanumihardjo, (2004), who demonstrated that vitamin A might be very harmful and act as a teratogen for pregnant women especially those who depend on food rich in this vitamin. So, they recommended a routine monitor of liver serum, reserve, and milk vitamin A concentration in pregnant women to prevent both hypo- and hypervitaminosis A in fetuses. In the same year (2004), Hodgson, also showed that the exposure to RA caused severe damage to the liver cells and produced hepatotoxicity. Barandeh et al., (2019) results are also in agreement with the results of the current study, they recorded disruption of embryonic liver cells and parenchyma caused by RA intake. But the present results are in disagreement with the results obtained by Aguwa and his colleagues, (2016), they demonstrated that 400 and $500 \mathrm{mg} / \mathrm{kg}$ vitamin A treated group recorded non-significant differences in the liver histological features of as compared to the control group.

The present results can be explained as demonstrated by Erkelens \& Mebius, (2017), that the effect of RA is mediated by two major groups of peptides; these are nuclear receptor proteins and cytoplasmic binding proteins. It is well known that there are two members of RA receptors, the RA receptors (RARs) and the retinoid X receptors (RXRs). RAR and their ligands may be involved in normal and abnormal embryonic development (Kam et al., 2012). Also, both RA receptor's families exhibit a very definite spatial and temporal distribution within 
developing embryo (Mark et al., 2009). Therefore, Kam et al., (2012) suggested that RA binds to the cytoplasmic receptors to enter the nucleus and bind to RAR to promote gene expression required for embryonic liver cell growth and differentiation.

The result of the current study also showed that RA caused fatty degeneration in the liver tissue and resulted in hepatocellular steatosis (fatty liver disease), hypertrophy of hepatocyte, vacuolar degeneration of hepatocytes, and inflammation of the liver. Steatosis as shown by Green and Hodson (2014), Mulder et al., (2015), and Nassir et al., (2015), meaning the accumulation of lipid droplet within hepatocytes and is considered pathologic condition when it affects more than 5\% of hepatocytes. Morphologically, steatosis hepatocytes are classified into macrovesicular steatosis in this one large lipid droplets filling up the hepatocyte and displacing the nucleus to the cell periphery and microvesicular steatosis when multiple small lipid droplets are present in the hepatocyte and giving the cytoplasm a foamy appearance. These two types of cells were recorded in the present study.

In the normal liver, retinol (which is mainly dietary-derived fat-soluble signaling molecule of vitamin A) is stored as a characteristic lipid droplet by hepatic stellate cells (HSCs) in the space of Disse and from which they are released and transported regularly to the target tissues as retinol-binding protein (RBP). In the normal animal, HSCs account for $50-60 \%$ of the total retinoid's storage in the entire body, these cells may be triggered in response to different kind of injuries, and may form a myofibroblast-like phenotype. (Shirakami et al., 2012; Mawson, 2016). Reynaert, (2002), showed that when HSCs are activated, these cells express the gene of smooth muscle $\alpha$ actin and functionally produce an elevated quantity of extracellular matrix components and matrix-degrading enzymes. In the liver, excess vitamin A is stored in HSCs, and accumulation can cause their activation and hypertrophy, increase in collagen formation, fibrosis, and liver damage the toxicity is dose-related and can be reproduced in animal models (Seegmiller et al., 1997).

Furthermore, present study results indicated that RA caused fatty change which noticed among other hepatotoxic injuries, this observation is in agreement with Thoolen et al., (2010), in both animals and man, they revealed that fatty changes can be produced along with a combination of other hepatotoxic damages such as, chronic liver toxicity, inflammation, degeneration, and necrosis; or nutritional disorders such as, diet and excess vitamin A

5. Conclusions, RA caused variable degrees of degeneration and destruction of the liver tissues of adult female (mother) and their prenatal. The most important effects of RA are causing hepatocellular steatosis, hypertrophy, and inflammation, and when RA giving during the critical periods of embryonic development, caused harmful effects on the developing liver, therefore treatment with RA should be avoided at any stage of gestation.

\section{Acknowledgements}

The authors would like to acknowledge the Head and staff of the Biology Department, Faculty of Science, University of Zakho, for their assistance and support in this research.

\section{References}

Aguwa, U. S., Owoeye, O., Olu, S. I., \& Ukoba, O. (2016), “Teratogenic effect of maternal vitamin A consumption on the liver, limbs and other morphological parameters of the pups of wistar rats", International Journal of Basic, Applied and Innovative Research 5(4), 130-137.

Babatola AO, Olatunya OS, Ogundare EO, Ajite AB, Oluwayemi IO, Thomas AA, Taiwo AB, Fatunla OA, Komolafe AK, \& Alfred A. (2019), "Acute hypervitaminosis A misdiagnosed as malaria in a 7-year-old Nigerian boy", International Medical Case Reports Journal 12, 213-2016.

Bancroft, J. D., \& Gamble, M. (Eds.). (2008), "Theory and practice of histological techniques", Elsevier health sciences.

Barandeh, B., Amini Mahabadi, J., Azadbakht, M., Gheibi Hayat, S. M., \& Amini, A. (2019), "The protective effects of curcumin on cytotoxic and teratogenic activity of retinoic acid in mouse embryonic liver", Journal of Cellular Biochemistry 120(12), 19371-19376.

Blomhoff, R., \& Blomhoff, H. K. (2006), "Overview of retinoid metabolism and function", Journal of Neurobiology 66(7), 606-630.

Canete, A., Cano, E., Muñoz-Chápuli, R., \& Carmona, R. (2017), "Role of vitamin A/retinoic acid in regulation of embryonic and adult hematopoiesis", Nutrients 9(2), 159. doi: 10.3390/nu9020159.

Cassani, B., Villablanca, E. J., De Calisto, J., Wang, S., \& Mora, J. R. (2012), "Vitamin A and immune regulation: role of retinoic acid in gut-associated dendritic cell education, immune protection and tolerance", Molecular Aspects of Medicine 33(1), 63-76.

Duncan, D. B. (1955)," Multiple range and multiple F tests", Biometrics 11(1), 1-42.

Erkelens, M. N., \& Mebius, R. E. (2017), "Retinoic acid and immune homeostasis: a balancing act", Trends in Immunology 38(3), 168-180.

Green, C. J., \& Hodson, L. (2014), “The influence of dietary fat on liver fat accumulation”, Nutrients 6(11), 5018- 
5033.

Guyton, A. C., \& Hall, J. E. (2006), “Textbook of medical physiology” $11^{\text {th }}$ ed. Philadelphia, Perm: Elsevier Saunders.

Haaker, M. W., Vaandrager, A. B., \& Helms, J. B. (2020), "Retinoids in health and disease: A role for hepatic stellate cells in affecting retinoid levels", Biochimica et Biophysica Acta (BBA)-Molecular and Cell Biology of Lipids 1865, 158674-158685

Hodgson, E. (2004), “A textbook of modern toxicology”, $3^{\text {rd }}$ edition. John Wiley and Sons, Inc, New Jersey. pp 203-211.

Hunt, J. R. (1996). "Teratogenicity of high vitamin A intake”. The New England Journal of Medicine, 334(18), 1197.

Kam, R. K. T., Deng, Y., Chen, Y., \& Zhao, H. (2012), "Retinoic acid synthesis and functions in early embryonic development", Cell \& Bioscience 2(1):11. doi: 10.1186/2045-3701-2-11.

Kelly, G. M., \& Drysdale, T. A. (2015),"Retinoic acid and the development of the endoderm", Journal of Developmental Biology 3(2), 25-56.

Kessel, M., \& Gruss, P. (1991), "Homeotic transformations of murine vertebrae and concomitant alteration of Hox codes induced by retinoic acid", Cell 67(1), 89-104.

Khaksary-Mahabady, M., Ranjbar, R., Najafzadeh-Varzi, H., Mohammadian, B., \& Gohari-Behbahani, N. (2018), "Protective Effect of Quercetin on Histomorphometric Changes in Kidney of Retinoid Acid-Treated Rat Fetuses", International Journal of Morphology 36(1),338-344.

Lammer, E. J., Chen, D. T., Hoar, R. M., Agnish, N. D., Benke, P. J., Braun, J. T., \& Richard, J. M. (1985), "Retinoic acid embryopathy", New England Journal of Medicine 313(14), 837-841.

Linney, E., Donerly, S., Mackey, L., \& Dobbs-McAuliffe, B. (2011), "The negative side of retinoic acid receptors", Neurotoxicology and Teratology 33(6), 631-640.

Mahassni, S., \& Al-Shaikh, N. (2014), "Effects of vitamin A overdose on rat's organs involved in immunity and vitamin A storage", Acta Alimentaria 43(3), 452-458.

Mao, G. E., Collins, M. D., \& Derguini, F. (2000), "Teratogenicity, tissue distribution, and metabolism of the retro-retinoids, 14-hydroxy-4, 14-retro-retinol and anhydroretinol, in the C57BL/6J mouse", Toxicology and Applied Pharmacology 163(1), 38-49.

Mark, M., Ghyselinck, N. B., \& Chambon, P. (2009), "Function of retinoic acid receptors during embryonic development", Nuclear Receptor Signaling 7(1), DOI: 10.1621/nrs.07002| Page 1 of 15

Mawson, A. R. (2016), “A role for the liver in parturition and preterm birth”, Journal of Translational Science 2(3), 154-159.

McMahon, A. P. (2016), "Development of the mammalian kidney", In Current topics in Developmental Biology (Vol. 117, pp. 31-64). Academic Press.

Mehrotra, N., \& Shah, G. L. (2004), "Effect of prenatal vitamin A in low doses on the liver and kidney of rat fetuses-A histological study", J. Anat. Soc. India 53(2), 25-28.

Moore, K. L., \& Dalley, A. F. (2018). “Clinically oriented anatomy”. Wolters kluwer india Pvt Ltd.

Morriss-Kay, G. M., Murphy, P. O., Hill, R. E., \& Davidson, D. R. (1991), "Effects of retinoic acid excess on expression of Hox-2.9 and Krox-20 and on morphological segmentation in the hindbrain of mouse embryos", The EMBO Journal 10(10), 2985-2995.

Mulder, P., Liang, W., Wielinga, P. Y., Verschuren, L., Toet, K., Havekes, L. M., \& Kleemann, R. (2015), "Macrovesicular steatosis is associated with development of lobular inflammation and fibrosis in diet-induced non-alcoholic steatohepatitis (NASH)", Inflammation and Cell Signaling 2(3), [e804]. https://doi.org/10.14800/ics.804

Naseer U. \& Tahir M. (2012), "Effects of vitamin A on fetal kidneys in albino mice: a histological study", Pakistan J. Zool. 44(4): 1045-1050.

Nassir, F., Rector, R. S., Hammoud, G. M., \& Ibdah, J. A. (2015), "Pathogenesis and prevention of hepatic steatosis", Gastroenterology \& Hepatology 11(3), 167-175.

National Institutes of Health (NIH). (2017), "Liver Tox: clinical and research information on drug-induced liver injury", Nih. gov https://livertox. nih. gov.

Noori, B. H., \& Waheed, I.N. (2020), "The effects of retinoic acid on the kidney tissues of adult female albino mice and their prenatal fetuses": A histological study, (Unpublished data).

Okano, J., Levy, C., Lichti, U., Sun, H. W., Yuspa, S. H., Sakai, Y., \& Morasso, M. I. (2012), “Cutaneous retinoic acid levels determine hair follicle development and downgrowth", Journal of Biological Chemistry 287(47), 39304-39315.

Piersma, A. H., Hessel, E. V., \& Staal, Y. C. (2017), "Retinoic acid in developmental toxicology: teratogen, morphogen and biomarker", Reproductive Toxicology 72, 53-61.

Reynaert, H., Thompson, M. G., Thomas, T., \& Geerts, A. (2002), "Hepatic stellate cells: role in microcirculation and pathophysiology of portal hypertension", Gut 50(4), 571-581. 
Roberts, C. (2020)," Regulating Retinoic Acid Availability during Development and Regeneration: The Role of the CYP26 Enzymes", Journal of Developmental Biology 8(1), 6. 8; doi:10.3390/jdb8010006

Ross, D. A. (2002), "Recommendations for vitamin A supplementation", The Journal of Nutrition 132(9), 2902S2906S.

Rugh, R. (1968), “The mouse; its reproduction and development”, Burgess Publishing Company. America.

Rutkowski, M., \& Grzegorczyk, K. (2012), “Adverse effects of antioxidative vitamins" International Journal of Occupational Medicine and Environmental Health 25(2), 105-121.

Saeed, A., Dullaart, R. P., Schreuder, T. C., Blokzijl, H., \& Faber, K. N. (2018), "Disturbed vitamin A metabolism in non-alcoholic fatty liver disease (NAFLD)", Nutrients 10(1), 29. doi:10.3390/nu10010029

Schreiber, R., Taschler, U., Preiss-Landl, K., Wongsiriroj, N., Zimmermann, R., \& Lass, A. (2012), "Retinyl ester hydrolases and their roles in vitamin A homeostasis", Biochimica et Biophysica Acta (BBA)-Molecular and Cell Biology of Lipids 1821(1), 113-123.

Seegmiller, R. E., Ford, W. H., Carter, M. W., Mitala, J. J., and Powers Jr, (1997), “A developmental toxicity study of tretinoin administered topically and orally to pregnant Wistar rats", Journal of the American Academy of Dermatology 36(3), S60-S66.

Shirakami, Y., Lee, S. A., Clugston, R. D., \& Blaner, W. S. (2012), "Hepatic metabolism of retinoids and disease associations", Biochimica et Biophysica Acta (BBA)-Molecular and Cell Biology of Lipids 1821(1), 124-136.

Sporn, M. B., \& Roberts, A. B. (1991), "Interactions of retinoids and transforming growth factor-beta in regulation of cell differentiation and proliferation", Mol Endocrinol 5,3-7.

Stromland, K., Miller, M., \& Cook, C. (1991), “Ocular teratology”, Surv Ophthalmol 35:429-446.

Summers, J. A. (2019), 'Retinoic Acid in Ocular Growth Regulation, In Vitamin A. DOI: 10.5772 /intechopen. 84586

Suuberg, A. (2019), Adverse Effects of Isotretinoin (13-cis-Retinoic Acid) on the Visual System, Available at SSRN 3340726

Tanumihardjo, S. A. (2004), “Assessing vitamin A status: past, present and future” The Journal of Nutrition 134(1), 290S-293S

Thoolen, B., Maronpot, R. R., Harada, T., Nyska, A., Rousseaux, C., Nolte, T., Malarkey D.E., Kaufmann, W.,Ttler, K., Deschl, U., Gregson, R., Vinlove, M., Brix, A., Nakae, D., Singh, B., Belpoggi, F., \&Ward, J. (2010), "Proliferative and nonproliferative lesions of the rat and mouse hepatobiliary system", Toxicologic Pathology 38(7), 5S-81S.

Vallerand, I. A., Lewinson, R. T., Farris, M. S., Sibley, C. D., Ramien, M. L., Bulloch, A. G. M., \& Patten, S. B. (2018), "Efficacy and adverse events of oral isotretinoin for acne: a systematic review", British Journal of Dermatology 178(1), 76-85.

Yousefi, B., \& Azizzadeh, F. (2010), "The histopathalogical effects of retinoic acid on the tissues", Pakistan Journal of Biological Sciences 13(9) 927-936.

Zasada, M., \& Budzisz, E. (2019), "Retinoids: active molecules influencing skin structure formation in cosmetic and dermatological treatments", Adv Dermatol Allergol 36(4), 392-397. 